\title{
Expression of Survivin in Basal-Like and Triple Negative Breast Carcinoma and Associations with Clinicopathological Parameters
}

\author{
Madatang A. ${ }^{a, c}$, Mohd Nafi S.N. ${ }^{a}$, Jaafar H. ${ }^{a}$, Wan Abdul Rahman W.F. ${ }^{a, b}$ \\ a'Department of Pathology, School of Medical Sciences, Universiti Sains Malaysia, Kelantan, Malaysia. \\ ${ }^{\mathrm{b}}$ Breast Cancer Awareness \& Research Unit, Hospital Universiti Sains Malaysia, Kelantan, Malaysia \\ 'Department of Pathology, Hospital Queen Elizabeth, Sabah, Malaysia
}

\begin{abstract}
INTRODUCTION: Triple negative breast carcinoma (TNBC) molecular subtype and its variant; basal-like triple negative (BLTN) carcinoma is an established poor prognostic indicator. The aim of this study is to analyse the survivin expression in TNBC and BLTN, and relating the results with clinicopathological parameters. MATERIALS
\end{abstract}

AND METHODS: We conducted a cross sectional study using 94 archived formalin-fixed paraffin embedded tissue blocks of invasive breast carcinoma, no special type (NST). Estrogen receptor (ER), progesterone receptor (PR) and human epidermal growth receptor 2 (HER2) were used as surrogate markers to classify the cases into molecular subtypes. Samples with triple negative phenotype (ER, PR and HER2 negative) were stained with CK 5/6 to identify the BLTN subtype. All the samples were also immunostained for survivin. RESULT: Out of 94 cases, 41.5\% (39 cases) were TNBC. Among the TNBC cases, only 41.0\% (16 cases) were BLTN subtype when they found to be positive for CK 5/6. Among 94 cases of invasive breast carcinoma, 28.7\% (27 cases) were survivin positive with (53.8\%) 21 cases were TNBC and (11\%) 6 cases were non-TNBC $(\mathrm{p}<0.001)$. Among 16 cases of BLTN subtype, only 8 cases were survivin positive $(p=0.752)$. Survivin expression was also statistically significant with tubule formation $(\mathrm{p}=0.029)$, nuclear pleomorphism $(\mathrm{p}=0.008)$, tumour grade $(\mathrm{p}=0.010)$, ER status $(\mathrm{p}<0.001)$ and PR status $(\mathrm{p}=0.001)$. CONCLUSION: Survivin expression was statistically significant in invasive breast carcinoma. Even though the expression was significantly high in TNBC, it is not related to whether it is a basal-like or non-basal-like variant.

KEYWORDS: Survivin, triple negative breast carcinoma, basal-like variant.

\section{INTRODUCTION}

Breast cancer is known to be a type of exceptionally clinical behaviour, outcome, and response to therapy. heterogeneous tumours. It is ranked as the most The basal-like breast carcinoma has gained attention common cancer affecting women worldwide. A among breast carcinomas subgroups because of its high recent molecular-based approach has clustered breast occurrence, weak baseline prognosis, tendency to affect carcinomas based on gene expression profiles. ${ }^{1}$ Luminal younger women and inadequacy of efficient targeted A, luminal B, HER2 over-expressive, normal breast-like therapies. This subtype comprises approximately and basal like are the five main classes of breast cancer $15-20 \%$ of breast cancers. 2,3 Characterisation for subgroups which demonstrate substantial variation in basal-like breast carcinomas requires two different

\section{Corresponding Author:}

Dr. Wan Faiziah Wan Abdul Rahman Department of Pathology, School of Medical Sciences, Universiti Sains Malaysia, Health Campus,

16150 Kota Bharu, Kelantan, Malaysia.

Tel No: +609-7676193

Email: wfaiziah@usm.my approaches, microarray-based expression profiling and immunohistochemistry (IHC). In arrays, the basal-like breast carcinomas are commonly ER-negative, PRnegative and lack of HER2 over expression, which is known as triple negative breast carcinoma (TNBC).4,6,7 Nevertheless, not all basal-like tumours are classified as TNBC carcinomas and not all TNBC carcinomas are 
known recent prognostic factors in these different breast cancer subtypes can enhance treatment options.

Apoptosis proteins inhibitor (IAP) family consists of survivin. This protein plays various roles in assisting cancer survival, which comprise of cell death suppression, cell-cycle control, particularly at the mitosis stage and cytoprotection. ${ }^{5}$ Findings from the previous studies proposed that tumour cells thrive with survivin due to their ability to withstand chemotherapy/radiation therapy and therefore, associated to poor prognosis. ${ }^{6,8}$ These results indicate that survivin could be a potential molecular target to combat cancerous growth in human.5,9 However, conflicting data exists on survivin prognostic effect in breast cancer due its different localization in both nuclear and cytoplasmic compartments. Relative to cytoplasmic, elevated expression of survivin in nuclear compartments has been shown to be associated with reduced overall survival (OS) and breast cancer-specific survival (BCSS). ${ }^{10,11}$

Recently, the prognostic significance of survivin within the molecular subtypes of breast carcinomas has been denoted. ${ }^{12-14}$ Despite that, research on the prognostic function of survivin in triple negative and basal breast carcinoma is minimal. It will be interesting to know the expression of survivin in basal-like breast carcinoma, which is the most interesting subtype of breast carcinoma that associated with poorer prognosis, shorter survival and a relatively high mortality rate. This research therefore aims to examine survivin expression in the two phenotypes of breast carcinomas involving human triple negative basal-like and triple negative nonbasal-like and to compare the prognostic effect on both phenotypes.

\section{MATERIALS AND METHODS}

\section{Breast cancer specimens}

Blocks of breast carcinoma tissues from lumpectomy, wide excision and mastectomy specimens of 94 patients diagnosed as invasive breast carcinoma, of no special type (NST) were acquired for the study from Hospital Universiti Sains Malaysia. Initially, the cancerous tissues were fixed using formalin and embedded with paraffin to make the tissue blocks. Details on age, gender, size of IMJM Volume 20 No.1, Jan 2021 tumour and status of the lymph node were collected from the medical record and Pathology Registry of patients. Ethical approval for this research was acquired from Ethical Committee of Universiti Sains Malaysia (USMKK/PPP/JEPeM 253.3.(13)).

The tissue slides were obtained to examine the tumour grades. The modified Scarff-Bloom Richardson grading system was applied to grade the breast tumours. ${ }^{13}$ Immunohistochemical stain slides for ER, PR and HER2 overexpression were collected and examined. For scoring, Allred Scoring System and Dako Hercep Test Protocol System were followed.15,16 All 94 samples were then stained with survivin and for all TNBC cases were stained with CK 5/6 to determine the basal-like variant. Cases with positive CK 5/6 were classified as Basal-like triple negative (BLTN) breast cancer.

\section{Immunohistochemical staining for Survivin and CK $5 / 6$}

Indirect immunohistochemistry staining for analysis of survivin and CK 5/6 was performed by using survivin and CK 5/6 primary antibodies. Survivin is a monoclonal antibody derived from a mouse [clone: 12C4, isotype: $\operatorname{IgG} 2 \mathrm{a}$, kappa, manufactured and marketed by Dako Denmark A/S with product code M3642]. The cellular staining is nuclear and/or cytoplasmic. CK 5/6 is a monoclonal antibody derived from a mouse, with clone D5/16 B4, manufactured and marketed by Dako Denmark A/S. The formalin-fixed, paraffin embedded tissues were cut into sections of $3 \mu$ thickness. Deparaffinization of tissue sections was done with the use of xylene. Then, graded alcohols were used for rinsing purpose. Endogenous peroxidase activity was inhibited in 3\% hydrogen peroxidase for 5 minutes incubation, accompanied by distilled water rinsing. Afterwards, the sections were immersed in citrate buffer, ph6.0 for survivin and ethylenediaminetetraacetic acid (EDTA), ph9.0 for CK 5/6 for antigen recovery, followed by 3-minute heating in pressure cooker (DAKO, Denmark). The primary survivin antibody was added to the sections with 1:50 dilution and overnight incubation was performed at $40^{\circ} \mathrm{C}$ using immunostainer squenza. Subsequently, CK 5/6 primary antibody was added with 1:50 dilutions to the sections and incubated for 1 hour at room temperature. These processes were followed by rinsing twice using tris buffer saline (TBS). 
Each section was treated with two drops of horseradish peroxidase (HRP) polymer followed by one-hour incubation at room temperature. Then, Diaminobenzidine (DAB), a chromogen from DAKO was added to the sections, followed by incubation for 1 minute and haematoxylin counterstain. Slides that were not stained with primary antibodies classified as negative controls and were tested with each staining batch, along with positive controls for each antibody. For survivin, reported case of colorectal cancer served as positive control and tonsil tissue was used for positive control of CK 5/6.

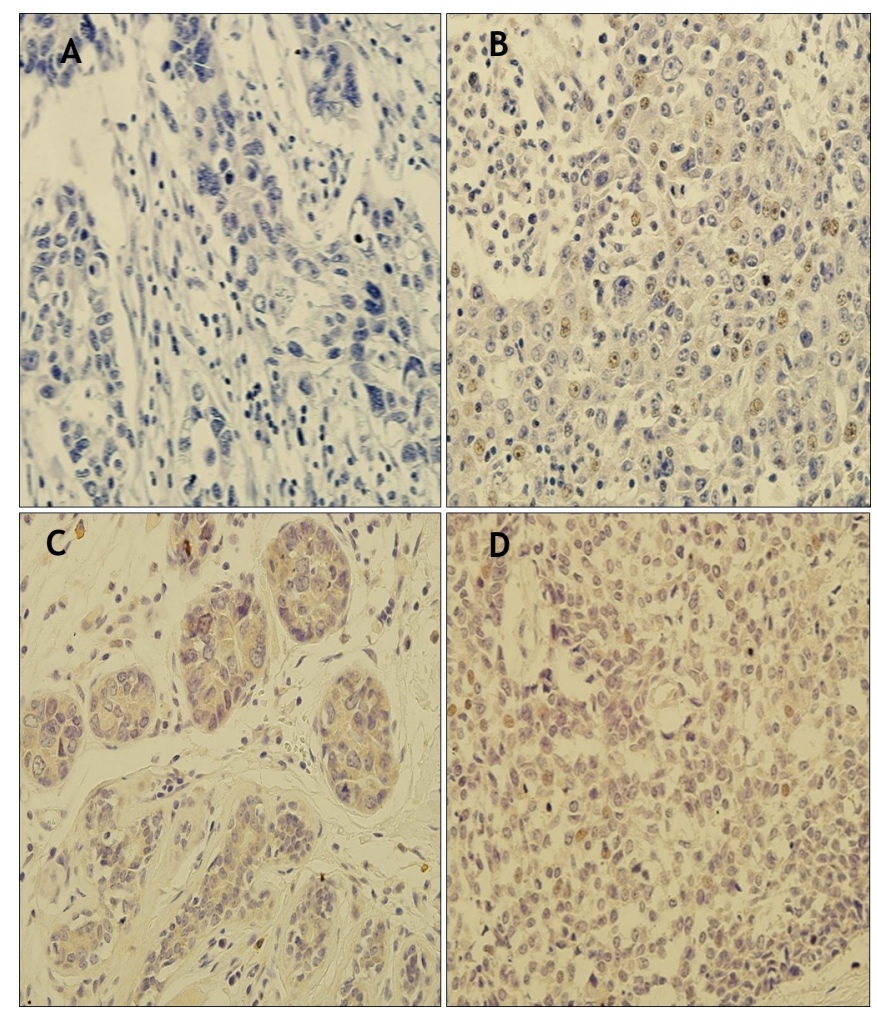

Figure 1: Representative images of survivin immunohistochemical staining expression pattern (magnification, x400). (A) Negative staining for nuclear and cytoplasmic expression of survivin. (B) Positive staining for nuclear expression of survivin. (C) Positive staining for cytoplasmic expression of survivin. (D) Positive staining for both nuclear and cytoplasmic survivin expression.

\section{Staining characteristic and scoring}

The expression of survivin in the different samples was analysed using a previously used method of scoring. ${ }^{17}$ The evaluation of positive tumour cells mean in percentage were performed by analysing the positive cells at 400x magnification in minimum of five areas, and allocated based on the following classification: (a) ' 0 ' $<5 \%$; (b) ' 1 ' 5\%-20\%; (c) ' 2 ' 21\%-50\%; (d) ' 3 ' 51\%-
$75 \%$; and (e) ' 4 ' $>75 \%$. The survivin immunostaining intensity was done semiquantitatively as weak (1+), moderate $(2+)$ and intense $(3+)$. Predominant pattern was included when scoring in the case of heterogeneous staining tumours. For each case, a weighted score was obtained by multiplying the positive tumour cells score with the score of staining intensity. Cases of $\geq 1$ weighted score were interpreted as positive and negative for $<1$ weighted score cases (Figure 1). Immunoreactivity microscopy was evaluated by two separate observers.

\section{Data analysis}

Statistical analysis was carried out using the programme version 20.0 of the Statistical Package for the Social Sciences (SPSS). All data were presented as frequency and percentage. Chi-square or Fisher-exact test was used to evaluate the association between expression of survivin in both basal and non-basal like triple negative breast carcinoma with other clinicopathological variables. In this research, the significance level was calculated when $\mathrm{p}$ value is $<0.05$.

\section{RESULTS}

\section{Incidence of Triple Negative Breast Cancer (TNBC) and basal-like triple negative (BLTN) subtypes}

39 out of 94 total cases involved in this research did not display immunoreactivity towards ER, PR and HER2. These cases were classified as Triple Negative Breast Cancer (TNBC) and the remaining 55 cases were classified as non-TNBC. Staining for CK $5 / 6$ was performed amongst TNBC to characterise the basal-like triple negative (BLTN) subtype. Sixteen out of 39 TNBC cases were positive for CK 5/6 and labelled as BLTN and 23 cases were labelled as non-BLTN.

The incidence of TNBC were significantly associated with clinicopathological features including race, nuclear pleomorphism, mitotic count, tubule formation, grade of tumour, hormonal status of ER, PR and HER2 (Table I). However, we observed no significant association between BLTN cases with all the clinicopathological factors variables (Table II). 
Table I. Associations between clinicopathological parameters with Triple Negative Breast Cancer (TNBC) and non-TNBC $(\mathrm{n}=94)$

\begin{tabular}{|c|c|c|c|c|c|c|}
\hline \multirow[t]{3}{*}{ Variable } & & \multicolumn{4}{|c|}{ n (\%) } & \multirow{3}{*}{$\begin{array}{l}\mathrm{p}- \\
\text { value }\end{array}$} \\
\hline & & \multirow{2}{*}{\multicolumn{2}{|c|}{$\begin{array}{l}\text { TNBC } \\
n=39\end{array}$}} & \multirow{2}{*}{\multicolumn{2}{|c|}{$\begin{array}{l}\text { Non-TNBC } \\
n=55\end{array}$}} & \\
\hline & & & & & & \\
\hline \multirow[t]{2}{*}{ Age } & $\leq 50$ years & 16 & (42.1) & 22 & $(57.9)$ & $>0.95$ \\
\hline & $\begin{array}{l}>50 \text { years } \\
\text { old }\end{array}$ & 23 & (41.1) & 33 & $(58.9)$ & \\
\hline \multirow[t]{3}{*}{ Race } & Malay & 37 & $(45.7)$ & 44 & $(54.3)$ & $0.027^{a}$ \\
\hline & Chinese & 1 & $(9.1)$ & 10 & $(90.9)$ & \\
\hline & Others & 1 & $(50.0)$ & 1 & $(50.0)$ & \\
\hline \multirow[t]{3}{*}{ Specimen } & Mastectomy & 31 & $(39.7)$ & 47 & $(60.3)$ & $0.212^{\mathrm{a}}$ \\
\hline & Lumpectomy & 7 & $(70.0)$ & 3 & $(30.0)$ & \\
\hline & $\begin{array}{l}\text { Wide } \\
\text { excision }\end{array}$ & 1 & $(16.7)$ & 5 & (83.3) & \\
\hline \multirow{3}{*}{$\begin{array}{l}\text { Tumour } \\
\text { size }(\mathrm{cm})\end{array}$} & $\leq 2$ & 2 & (22.2) & 7 & $(77.8)$ & 0.313 \\
\hline & $>2$ but $\leq 5$ & 18 & (39.1) & 28 & $(60.9)$ & \\
\hline & $>5$ & 19 & $(48.7)$ & 20 & $(51.3)$ & \\
\hline \multirow{3}{*}{$\begin{array}{l}\text { Nuclear } \\
\text { pleo- } \\
\text { morphism }\end{array}$} & $\begin{array}{l}\text { Score } 1 \\
\text { (mild) }\end{array}$ & 0 & $(0.0)$ & 5 & $(100.0)$ & $0.001^{a}$ \\
\hline & $\begin{array}{l}\text { Score } 2 \\
\text { (moderate) }\end{array}$ & 20 & (32.8) & 41 & $(67.2)$ & \\
\hline & $\begin{array}{l}\text { Score } 3 \\
\text { (marked) }\end{array}$ & 19 & $(67.9)$ & 9 & (32.1) & \\
\hline \multirow{3}{*}{$\begin{array}{l}\text { Mitotic } \\
\text { count }\end{array}$} & Score 1 & 5 & $(27.8)$ & 13 & $(72.2)$ & 0.008 \\
\hline & Score 2 & 4 & $(19.0)$ & 17 & $(81.0)$ & \\
\hline & Score 3 & 30 & (54.5) & 25 & (45.5) & \\
\hline \multirow[t]{3}{*}{$\begin{array}{l}\text { Tubule } \\
\text { formation }\end{array}$} & $\begin{array}{l}\text { Score } 1 \\
(70 \%)\end{array}$ & 2 & $(25.0)$ & 6 & $(75.0)$ & $0.004 a$ \\
\hline & $\begin{array}{l}\text { Score } 2 \\
(10-70 \%)\end{array}$ & 4 & (16.7) & 20 & (83.3) & \\
\hline & $\begin{array}{l}\text { Score } 3 \\
(<10 \%)\end{array}$ & 33 & (53.2) & 29 & $(46.8)$ & \\
\hline \multirow{3}{*}{$\begin{array}{l}\text { Tumour } \\
\text { grade }\end{array}$} & 1 (Score 3-5) & 2 & $(16.7)$ & 10 & (83.3) & $<0.001$ \\
\hline & 2 (Score 6-7) & 7 & $(21.2)$ & 26 & (78.8) & \\
\hline & 3 (Score 8-9) & 30 & (61.2) & 19 & (38.8) & \\
\hline \multirow{3}{*}{$\begin{array}{l}\mathrm{LN} \\
\text { metastases }\end{array}$} & Present & 20 & $(37.0)$ & 34 & $(63.0)$ & 0.173 \\
\hline & Absent & 9 & (37.5) & 15 & $(62.5)$ & \\
\hline & Unknown & 10 & (62.5) & 6 & $(37.5)$ & \\
\hline \multirow[t]{2}{*}{ ER status } & Positive & 0 & $(0.0)$ & 35 & $(100.0)$ & $<0.001$ \\
\hline & Negative & 39 & $(66.1)$ & 20 & $(33.9)$ & \\
\hline \multirow[t]{2}{*}{ PR status } & Positive & 0 & $(0.0)$ & 35 & $(100.0)$ & $<0.001$ \\
\hline & Negative & 39 & $(62.9)$ & 23 & (37.1) & \\
\hline \multirow{3}{*}{$\begin{array}{l}\text { HER2 } \\
\text { status }\end{array}$} & Positive & 0 & $(0.0)$ & 27 & $(100.0)$ & $<0.001$ \\
\hline & Negative & 39 & (68.4) & 18 & (31.6) & \\
\hline & Equivocal & 0 & $(0.0)$ & 10 & $(100.0)$ & \\
\hline
\end{tabular}

aFisher-exact test $\mathrm{p}$-value
Survivin expression in breast cancer subtypes and correlation with patient outcomes

The level of survivin expression was evaluated in primary invasive breast cancers. Of the 94 tumours evaluated for survivin expression, 27 displayed positive expression (28.7\%) and 67 were negative expression (71.3\%). Subcellular localization of survivin-positive nuclear staining was accounted for $16 / 27$, while positive cytoplasmic staining was accounted for only $8 / 27$. Three out of 27 tumours reported to be positive for both cytoplasmic and nuclear staining.

21 TNBCs $(53.8 \%)$ and 6 non-TNBCs $(11 \%)$ demonstrated positive staining for survivin $(\mathrm{p}=<0.001)$ (Table III). In addition, 8 BLTN subtypes and 13 nonBLTN subtypes showed positive survivin staining $(p=0.752)$ (Table III). The expression of survivin was found to be correlated with nuclear pleomorphism ( $\mathrm{p}=0.008)$, tubular formation $(\mathrm{p}=0.029)$, grade of tumour $(p=0.010)$, PR status $(p=0.001)$ and ER status $(\mathrm{p}=<0.001)$ (Table IV).

\section{DISCUSSION}

Molecular classification of breast cancer is seen to be a useful tool for recent cancer management. IHC markers such as CK 5/6, EGFR, ER, PR and HER2 are generally used in breast cancer subtyping by means of immunohistochemistry method. However, in our research, only CK 5/6, ER, PR, and HER2 staining were performed to segregate the molecular subtypes between TNBC (39/94 cases) and BLTN (16/39 cases).

IHC staining for EGFR was not done, however the cases were referred as normal-like tumour subtypes. There were significant associations between race, mitotic count, nuclear pleomorphism, grade of tumour, formation of tubule, ER, PR and HER2 hormonal status with TNBC cases. However, there was no significant association found between all clinicopathological variables with BLTN subgroup. 
Table II. Associations between clinicopathological parameters with basal-like triple negative (BLTN) and non-BLTN ( $\mathrm{n}=39)$

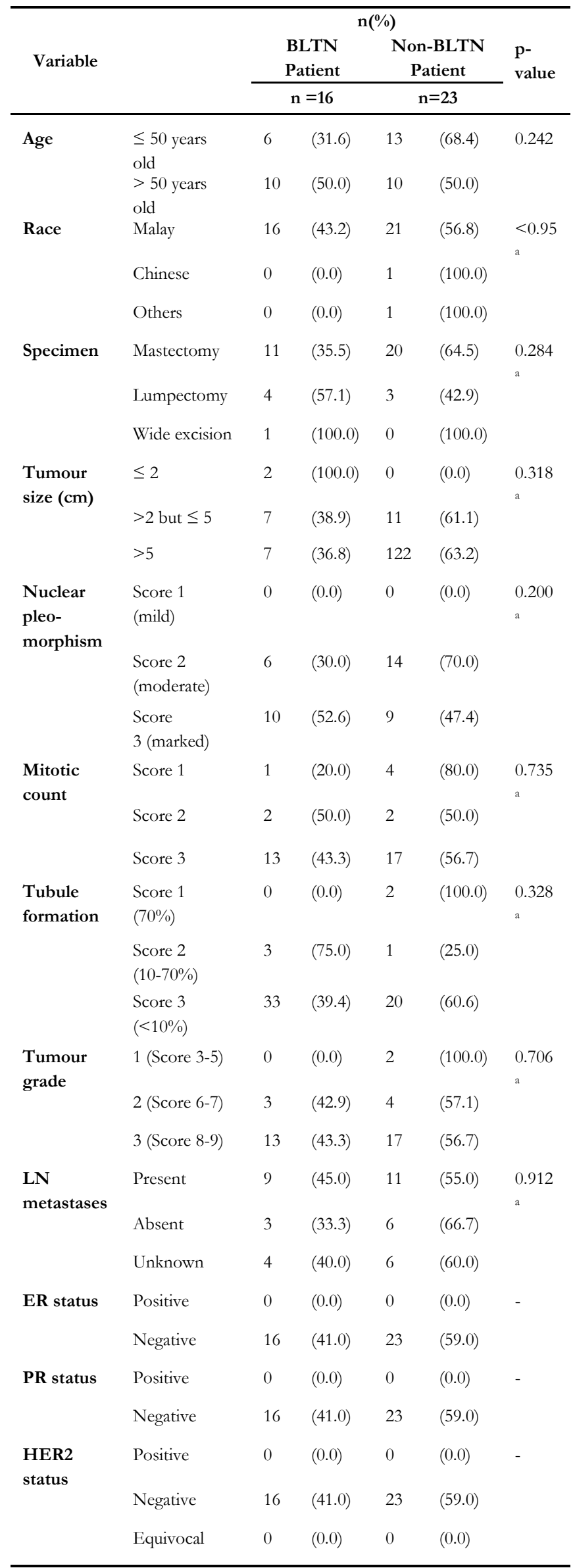

aFisher-exact test $\mathrm{p}$-value

Others: Chi-square test p-value
Table III. Comparison of survivin expression in Triple Negative Breast Cancer (TNBC) and basal-like triple negative (BLTN)

\begin{tabular}{llcl}
\hline & \multicolumn{2}{c}{$\begin{array}{c}\text { SURVIVIN EXPRESION, } \\
\text { (\%) }\end{array}$} & \multirow{2}{*}{ p-value } \\
\cline { 2 - 3 } & POSITIVE & NEGATIVE & \\
\hline TNBC & $21(53.8)$ & $18(46.2)$ & $<0.001$ \\
Non-TNBC & $6(11.0)$ & $49(89.0)$ & \\
BLTN & $8(50.0)$ & $8(50.0)$ & 0.752 \\
Non-BLTN & $13(56.5)$ & $10(43.5)$ & \\
\hline
\end{tabular}

The importance of survivin expression in breast carcinoma as a marker in prognosis has been well studied. ${ }^{8-15}$ However, researches on the survivin importance for BLTN and TNBC subtypes of breast carcinomas, focusing on its significance as a prognostic factor is still limited. In our study, survivin expression was detected in $29.0 \%$ (27/94) of the infiltrating breast carcinoma. The cases were considered low as compared to previous local study. ${ }^{15}$

A significant expression of survivin was detected among TNBC subtypes (53.8\%) as compared to non-TNBC $(11.0 \%)$ (Table III). This suggests a possible role of survivin as a prognostic marker for TNBC that is normally associated with the aggressive phenotype. ${ }^{1,4,12,14}$ In contrast, there was no significant correlation of survivin between BLTN vs non-BLTN subtypes (Table III). It was previously reported that survivin to be predominantly localised in nuclear and cytoplasmic compartments. ${ }^{16-19}$ Our study also observed similar subcellular localization patterns of survivin in most of our cases (Figure 1).

The correlation between expression of survivin and nuclear pleomorphism $(\mathrm{p}=0.008)$, grade of tumour $(p=0.010)$, formation of tubule $(p=0.029)$, status of ER $(p=<0.001)$ and status of PR $(p=0.001)$ were found to be significant. Results from this study are consistent with existing studies which showed significant associations between expression of survivin with negative prognostic factors i.e. negative hormonal status of both ER and PR, increased size of tumour, larger grade of tumour, late stage of tumour and metastases of lymph node, ${ }^{14,17,19,20,22,23}$ There was no notable relationship between expression of survivin with ethnicity, age, size of tumours, mitotic count, tubule 
Table IV. Associations between survivin expression and clinicopathological features $(\mathrm{n}=94)$

\begin{tabular}{|c|c|c|c|}
\hline \multirow{2}{*}{ Variable } & \multicolumn{2}{|c|}{$\begin{array}{c}\text { SURVIVIN EXPRESSION } \\
\mathbf{n}(\%)\end{array}$} & \multirow{2}{*}{$\begin{array}{l}\mathrm{p}- \\
\text { value }\end{array}$} \\
\hline & $\begin{array}{c}\text { Positive } \\
\text { n }=27\end{array}$ & $\begin{array}{c}\text { Negative } \\
n=67\end{array}$ & \\
\hline
\end{tabular}

\begin{tabular}{|c|c|c|c|c|c|c|}
\hline Age & $\begin{array}{l}\leq 50 \text { years } \\
\text { old } \\
>50 \text { years } \\
\text { old }\end{array}$ & 12 & (26.1) & 33 & $\begin{array}{l}(73.9) \\
(68.8)\end{array}$ & 0.625 \\
\hline \multirow[t]{3}{*}{ Race } & Malay & 26 & (32.1) & 55 & $(67.9)$ & $0.234^{a}$ \\
\hline & Chinese & 1 & $(9.1)$ & 10 & $(90.9)$ & \\
\hline & Others & 0 & $(0.0)$ & 12 & $(100.0)$ & \\
\hline \multirow[t]{3}{*}{ Specimen } & Mastectomy & 22 & $(28.2)$ & 56 & $(71.8)$ & $0.477^{a}$ \\
\hline & Lumpectomy & 2 & (20.0) & 8 & $(80.0)$ & \\
\hline & Wide excision & 3 & $(50.0)$ & 3 & $(50.0)$ & \\
\hline \multirow[t]{3}{*}{$\begin{array}{l}\text { Tumour } \\
\text { size }(\mathrm{cm})\end{array}$} & $\leq 2$ & 1 & (11.1) & 8 & $(88.9)$ & 0.47 \\
\hline & $>2$ but $\leq 5$ & 14 & (30.4) & 32 & (69.6) & \\
\hline & $>5$ & 12 & $(30.8)$ & 27 & $(69.2)$ & \\
\hline \multirow[t]{3}{*}{$\begin{array}{l}\text { Nuclear } \\
\text { pleo- } \\
\text { morphism }\end{array}$} & $\begin{array}{l}\text { Score } 1 \\
\text { (mild) }\end{array}$ & 0 & $(0.0)$ & 5 & (100.0) & $0.008^{a}$ \\
\hline & $\begin{array}{l}\text { Score } 2 \\
\text { (moderate) }\end{array}$ & 13 & (21.3) & 48 & (78.7) & \\
\hline & $\begin{array}{l}\text { Score } 3 \\
\text { (marked) }\end{array}$ & 14 & $(50.0)$ & 14 & $(50.0)$ & \\
\hline \multirow[t]{3}{*}{ Mitotic } & Score 1 & 3 & (16.7) & 15 & (83.3) & 0.296 \\
\hline & Score 2 & 5 & (23.8) & 16 & $(76.2)$ & \\
\hline & Score 3 & 19 & (34.5) & 36 & (65.5) & \\
\hline \multirow[t]{3}{*}{$\begin{array}{l}\text { Tubule } \\
\text { formation }\end{array}$} & $\begin{array}{l}\text { Score } 1 \\
(70 \%)\end{array}$ & 0 & $(0.0)$ & 8 & $(100.0)$ & 0.029 \\
\hline & $\begin{array}{l}\text { Score } 2 \\
(10-70 \%)\end{array}$ & 4 & (16.7) & 20 & (83.3) & \\
\hline & $\begin{array}{l}\text { Score } 3 \\
(<10 \%)\end{array}$ & 23 & (37.1) & 39 & $(62.9)$ & \\
\hline \multirow[t]{3}{*}{$\begin{array}{l}\text { Tumour } \\
\text { grade }\end{array}$} & $\begin{array}{l}1 \\
\text { (Score 3-5) }\end{array}$ & 0 & $(0.0)$ & 12 & $(100.0)$ & 0.01 \\
\hline & $\begin{array}{l}2 \\
(\text { Score 6-7) }\end{array}$ & 7 & $(21.2)$ & 26 & (78.8) & \\
\hline & $\begin{array}{l}3 \\
\text { (Score 8-9) }\end{array}$ & 20 & $(40.8)$ & 29 & $(59.2)$ & \\
\hline \multirow[t]{3}{*}{$\begin{array}{l}\text { LN } \\
\text { metastases }\end{array}$} & Present & 12 & (22.2) & 42 & $(77.8)$ & 0.209 \\
\hline & Absent & 10 & (41.7) & 14 & (58.3) & \\
\hline & Unknown & 5 & $(31.2)$ & 11 & $(68.8)$ & \\
\hline \multirow[t]{2}{*}{ ER status } & Positive & 2 & $(5.7)$ & 33 & (94.3) & $<0.001$ \\
\hline & Negative & 25 & (42.4) & 34 & (57.6) & \\
\hline \multirow[t]{2}{*}{ PR status } & Positive & 2 & $(6.2)$ & 30 & (93.8) & 0.001 \\
\hline & Negative & 25 & $(40.3)$ & 37 & $(59.7)$ & \\
\hline \multirow[t]{3}{*}{ HER2 } & Positive & 5 & (18.5) & 22 & (81.5) & 0.085 \\
\hline & Negative & 21 & (36.8) & 36 & $(63.2)$ & \\
\hline & Equivocal & 1 & (10.0) & 9 & $(90.0)$ & \\
\hline
\end{tabular}

a Fisher-exact test p-value

Others: Chi-square test p-value formation, tumour grade, lymph nodes metastases or number of positive nodes, which confirmed previous findings. ${ }^{17,21}$ However, another study reported a significant relationship between high survivin concentrations and ductal histologic type and younger age. ${ }^{14,20}$

In conclusion, our results indicated that survivin was significantly expressed in TNBC subtype. However, there was no prognostic impact of survivin in patient with BLTN breast carcinoma. Considering the fact that the breast carcinoma occurrence of triple negative and basal-like subtypes is only about $12-17 \%$, multicentre studies are more appropriate to get a larger study sample.

\section{ACKNOWLEDGEMENT}

This research was supported by a Short-term Grant 304/PPSP/61313011 from Universiti Sains Malaysia.

\section{REFERENCES}

1. Sorlie T, Perou CM, Tibshirani R, et al. Gene expression patterns of breast carcinomas distinguish tumor subclasses with clinical implications. Proc Natl Acad Sci USA. 2001; 98:10869-74.

2. Carey LA, Perou CM, Livasy CA, et al. Race, breast cancer subtypes, and survival in the Carolina Breast Cancer Study. JAMA, 2006; 295:2492-502.

3 Sandhu R, Parker JS, Jones WD, Livasy CA, Coleman WB. Microarray-Based Gene Expression Profiling for Molecular Classification of Breast Cancer and Identification of New Targets for Therapy. Laboratory Medicine. 2010; 41:364-72.

4. Prat A, Adamo B, Cheang MC, et al. Molecular characterization of basal-like and non-basal-like triple-negative breast cancer. Oncologist. 2013; 18:123-33.

5. Duffy MJ, O'Donovan N, Brennan DJ, et al. Survivin: a promising tumor biomarker. Cancer Lett. 2007; 249:49-60.

6. Ambrosini G, Adida C, Altieri DC. A novel antiapoptosis gene, survivin, expressed in cancer and lymphoma. Nat Med. 1997; 3:917-21.

7. Hubalek M, Czech T, Müller H. Biological Subtypes of Triple-Negative Breast Cancer. Breast Care. 
2017; 12:8-14

8. Nassar A, Sexton D, Cotsonis G, et al. Survivin expression in breast carcinoma: correlation with apoptosis and prognosis. Appl Immunohistochem Mol Morphol. 2008; 16:221-6.

9. Yamamoto H, Ngan CY, Monden M. Cancer cells survive with survivin. Cancer Sci. 2008; 99:170914.

10. Rexhepaj E, Jirstrom K, O'Connor DP, et al. Validation of cytoplasmic-to-nuclear ratio of survivin as an indicator of improved prognosis in breast cancer. BMC Cancer. 2010; 10:639.

11. Brennan DJ, Rexhepaj E, O'Brien SL, et al. Altered cytoplasmic-to-nuclear ratio of survivin is a prognostic indicator in breast cancer. Clin Cancer Res. 2008; 14(9):2681-9.

12. Sarti M, Pinton S, Limoni C, et al. Differential expression of testin and survivin in breast cancer subtypes. Oncol Rep. 2013; 30(2):824-32.

13. Dogu GG, Ozkan M, Ozturk F, et al. Triplenegative breast cancer: immunohistochemical correlation with basaloid markers and prognostic value of survivin. Med Oncol. 2010; 27(1):34-9.

14 Shaaban HM, Hafez NH, Ragab HM, Abadi AIE. Nuclear and Cytoplasmic Expression of Survivin in Breast Carcinoma: Correlation with Clinicopathological Parameters. International Journal of Cancer Research. 2016; 12:128-39.

15. Al-Joudi FS, Iskandar ZA, Imran AK. Survivin expression correlates with unfavourable prognoses in invasive ductal carcinoma of the breast. Med J Malaysia. 2007; 62:6-8.

16. Al-Joudi FS, Iskandar ZA, Hasnan J, et al. Expression of survivin and its clinicopathological correlations in invasive ductal carcinoma of the breast. Singapore Med J. 2007; 48:607-14.

17. Youssef NS, Hewedi IH, Abd Raboh NM. Immunohistochemical expression of survivin in breast carcinoma: relationship with clinicopathological parameters, proliferation and molecular classification. J Egypt Natl Canc Inst. 2008; 20:348-57.

18. Athanassiadou AM, Patsouris E, Tsipis A, Gonidi $\mathrm{M}$, Athanassiadou P.The significance of Survivin and Nectin-4 expression in the prognosis of breast carcinoma. Folia Histochemica Cytobiologica.

2011; 49:26-33.
19. Hegazy A. Clinicopathological significance and correlation of survivin, HER2 and BCL2 expression in breast carcinoma. Zagazig University Medical Journal. 2014; 20:883-98

20. Span PN, Tjan-Heijnen VC, Manders P, et al. High survivin predicts a poor response to endocrine therapy, but a good response to chemotherapy in advanced breast cancer. Breast Cancer Res Treat. 2006; 98:223-30.

21. Singh M, Bleile MJ, Shroyer AL, et al. Analysis of survivin expression in a spectrum of benign to malignant lesions of the breast. Appl Immunohistochem Mol Morphol. 2004; 12:296304.

22 Hinnis AR, Luckett JC, Walker RA. Survivin is an independent predictor of short-term survival in poor prognostic breast cancer patients. Br J Cancer. 2007; 96:639-45.

23. Sušac I, Ozretić $\mathrm{P}$, Gregorić $\mathrm{M}$, et al. Polymorphisms in Survivin (BIRC5 Gene) Are Associated with Age of Onset in Breast Cancer Patients. Journal of Oncology. 2019; (4):1-10. 